\title{
1 Applied phenomics and genomics for improving barley yellow dwarf resistance in winter
}

\section{2 wheat}

3

4 Paula Silva ${ }^{1,2}$, Byron Evers ${ }^{1}$, Alexandria Kieffaber ${ }^{1}, \mathrm{Xu}$ Wang $^{3}$, Richard Brown ${ }^{1}$, Liangliang

$5 \mathrm{Gao}^{1}$, Allan Fritz ${ }^{4}$, Jared Crain ${ }^{1}$, Jesse Poland ${ }^{1,5, \S}$

6

$7{ }^{1}$ Department of Plant Pathology, College of Agriculture, Kansas State University, Manhattan,

8 Kansas, 66506

$9 \quad{ }^{2}$ Programa Nacional de Cultivos de Secano, Instituto Nacional de Investigación Agropecuaria

10 (INIA), Estación Experimental La Estanzuela, Colonia, Uruguay, 70006

$11{ }^{3}$ Department of Agricultural and Biological Engineering, University of Florida, IFAS Gulf Coast

12 Research and Education Center, Wimauma, Florida, 33598

$13{ }^{4}$ Department of Agronomy, College of Agriculture, Kansas State University, Manhattan, Kansas,

1466506

$15{ }^{5}$ King Abdullah University of Science and Technology, Thuwal, Saudi Arabia

$16 \S$ corresponding author: jpoland@ksu.edu,jesse.poland@kaust.edu.sa

17

18 ORCID

19 Paula Silva: 0000-0003-2655-2949

20 Byron Evers: 0000-0003-1840-5842

21 Xu Wang: 0000-0002-7144-6865

22 Liangliang Gao: 0000-0002-8562-0027

23 Allan Fritz: 0000-0003-2574-8675

24 Jared Crain: 0000-0001-9484-8325

25 Jesse Poland: 0000-0002-7856-1399 
bioRxiv preprint doi: https://doi.org/10.1101/2022.01.05.475073; this version posted January 6, 2022. The copyright holder for this preprint

(which was not certified by peer review) is the author/funder, who has granted bioRxiv a license to display the preprint in perpetuity. It is made available under aCC-BY 4.0 International license.

27 Running title - Phenomics and genomics for BYD

28

29 Keywords: Barley yellow dwarf (BYD), High-throughput Phenotyping (HTP), Triticum

30 aestivum, Virus, Resistance, Tolerance, Genome-wide Association Mapping (GWAS), Genomic

31 Selection (GS)

32 


\section{Abstract}

34 Barley yellow dwarf (BYD) is one of the major viral diseases of cereals. Phenotyping BYD in

35 wheat is extremely challenging due to similarities to other biotic and abiotic stresses. Breeding

36 for resistance is additionally challenging as the wheat primary germplasm pool lacks genetic

37 resistance, with most of the few resistance genes named to date originating from a wild relative

38 species. The objectives of this study were to, i) evaluate the use of high-throughput phenotyping

39 (HTP) from unmanned aerial systems to improve BYD assessment and selection, ii) identify

40 genomic regions associated with BYD resistance, and iii) evaluate genomic prediction models

41 ability to predict BYD resistance. Up to 107 wheat lines were phenotyped during each of five

42 field seasons under both insecticide treated and untreated plots. Across all seasons, BYD

43 severity was lower with the insecticide treatment and plant height (PTHTM) and grain yield

44 (GY) showed increased values relative to untreated entries. Only $9.2 \%$ of the lines were positive

45 for the presence of the translocated segment carrying resistance gene $B d v 2$ on chromosome 7DL.

46 Despite the low frequency, this region was identified through association mapping. Furthermore,

47 we mapped a potentially novel genomic region for resistance on chromosome 5AS. Given the

48 variable heritability of the trait $(0.211-0.806)$, we obtained relatively good predictive ability for

49 BYD severity ranging between $0.06-0.26$. Including $B d v 2$ on the predictive model had a large

50 effect for predicting BYD but almost no effect for PTHTM and GY. This study was the first

51 attempt to characterize BYD using field-HTP and apply GS to predict the disease severity.

52 These methods have the potential to improve BYD characterization and identifying new sources

53 of resistance will be crucial for delivering BYD resistant germplasm. 


\section{Introduction}

55 Wheat (Triticum aestivum L.) is one of the most essential food crops in the world and is constantly threatened by several biotic stresses (Savary et al. 2019). Among the most important viral stresses is barley yellow dwarf (BYD). This disease is widespread across the world, caused by viruses and transmitted by aphids (Shah et al. 2012), and can cause significant yield reductions in susceptible cultivars. In Kansas, BYD is the fourth most significant wheat disease in terms of average estimated yield losses with an average yield loss of approximately $1 \%$ estimated over the past 20 years (Hollandbeck et al. 2019), equivalent to a loss of more than $\$ 10$ million per year. However, yield losses are highly variable ranging from 5\% to $80 \%$ in a single field depending on the environment, management practices, the host, and the genetic background, (Miller and Rasochová 1997; Perry et al. 2000; Gaunce and Bockus 2015). Moreover, the wide host range and the complex lifestyle of its vectors make BYD extremely difficult to manage, and different management strategies (e.g., planting date and control of vector populations) are inconsistent depending on climate and location (Bockus et al. 2016). Thus, in many production environments, particularly in the Central and Eastern regions of Kansas, BYD is often the most economically impactful disease.

Barley yellow dwarf disease symptoms are highly variable depending on the crop, variety, time, and developmental stage when the infection occurs, aphid pressure, and environmental conditions (Shah et al. 2012; Choudhury et al. 2019b). BYD characterization in the field is

74 extremely challenging as the symptoms can easily be confused with other viral disease symptoms such as wheat streak mosaic virus symptoms, nutrient deficiencies, or environmental stresses like waterlogging (Shah et al. 2012). Typical BYD symptoms can be observed at all levels of plant organization - leaf, roots, and flowers. Leaf discoloration in shades of yellow, red, or purple, specifically starting at the tip of the leaf and spreading from the margins toward the base is common as well as a reduction in chlorophyll content (Jensen and Van Sambeek 1972; D'arcy 1995). Often the entire plant visually appears stunted or dwarfed from a reduction

81 in biomass by reducing tiller numbers. Spike grain yield is decreased through a reduction in

82 kernels per spike and kernel weight which also affects grain quality (Riedell et al. 2003;

83 Choudhury et al. 2019b). Quality can be further reduced by a reduction in starch content (Peiris 
84 et al. 2019). Below ground effects of BYD have also been reported including reduced root

85 growth (Riedell et al. 2003).

87 Currently, there is no simple solution to control BYD (Walls et al. 2019), however, the use of

88 genetic resistance and tolerance is the most appealing and cost-effective option to control this

89 disease (Comeau and Haber 2002; Choudhury et al. 2017; 2019b). Resistance and tolerance

90 could be different genetic mechanisms, namely stopping virus replication and minimizing

91 disease symptoms respectively, but within this paper all mention of resistance includes both

92 genetic resistance and tolerance. Breeding strategies involving genetic resistance can target

93 either the aphids or the virus. Resistance to aphids can be achieved by three different strategies,

94 antixenosis, antibiosis, or tolerance (Girvin et al. 2017). To date, most breeding efforts have

95 been directed to the identification of viral tolerance, also known as 'field resistance', that refers

96 to the ability of the plant to yield under BYD infection and is associated with a reduction of

97 symptoms of infection independent of the virus titer (Foresman et al. 2016). Field resistance has

98 been reported to be polygenic, falling under the quantitative resistance class, where several genes

99 with very small effects control the resistance response (Qualset et al. 1973, Cisar et al. 1982;

100 Ayala et al. 2002; Choudhury et al. 2019a; c).

101

102 Presently, no major gene conferring immunity or a strong resistant phenotype to BYD has been

103 identified in bread wheat, and only four resistance genes have been described for BYD. Located

104 on chromosome 7DS, $B d v 1$ is the only gene described from the primary pool of wheat and was

105 originally identified in the wheat cultivar 'Anza' (Qualset et al. 1984; Singh et al. 1993). This

106 gene provides resistance to some but not all the viruses that cause BYD (Ayala-Navarrete and

107 Larkin 2011). The other three named genes were all introduced into wheat through wide

108 crossing from intermediate wheatgrass (Thinopyrum intermedium) (Ayala et al. 2001; Zhang et

$109 a l .2009) . B d v 2$ and $B d v 3$ are both located on a translocation segment on wheat chromosome

110 7DL (Brettell et al. 1988; Sharma et al. 1995), while Bdv4 is located on a translocation segment

111 on chromosome 2D (Larkin et al. 1995; Lin et al. 2007). Bdv2 was the first gene successfully

112 introgressed in wheat breeding programs from the tertiary gene pool for BYD resistance (Banks

113 et al. 1995) and deployed into varieties. 
115 In addition to the four known resistance genes, other genomic regions associated with BYD

116 resistance have been identified through genetic mapping. These regions have been described on

117 nearly all wheat chromosomes but have not been genetically characterized (Ayala et al. 2002;

118 Jarošová et al.2016; Choudhury et al. 2019a; b; c). Moreover, two recent studies have reported

119 that some of these new genomic regions display additive effects (Choudhury et al. 2019a; b).

120 Additive genetic effects had already been reported in lines combining $B d v 2$ and $B d v 4$ (Jahier et

121 al. 2009).

123 Taken together, research indicates that resistance genes to BYD in wheat are rare. With a lack of

124 major genes and difficulty to characterize resistance in the wheat pool likely due to the polygenic

125 nature of many small effect loci, identifying resistance has been limited. Nevertheless, breeding

126 programs have devoted large efforts for breeding BYD resistance due to the economic

127 importance of this disease, with some of the greatest success coming from wide crosses to the

128 tertiary gene pool.

130 Breeding for BYD resistance can be improved by applying strategies for more effective

131 evaluation and utilization of the identified resistance. To get a better understanding of BYD and

132 its quantitative nature, consistent and high-throughput methods are needed for the identification

133 of resistant wheat lines for large-scale selection in breeding programs (Aradottir and Crespo-

134 Herrera 2021). Effective selection on the quantitative resistance with low heritability can be

135 aided by the high-throughput genotyping, high-throughput phenotyping (HTP), or a combination

136 of both.

138 Access to high-density genetic markers at a very low-cost, owing to the rapid developments in

139 DNA sequencing, have enabled breeding programs to apply molecular breeding for quantitative

140 traits. Genomic selection (GS) is a powerful tool to breed for quantitative traits with complex

141 genetic architecture and low heritability (e.g., yield, quality, and diseases such as Fusarium head

142 blight), because it has greater power to capture loci with small effect compared with other

143 marker-assisted selection strategies (Meuwissen et al. 2001; Poland and Rutkoski 2016). In

144 addition to molecular data, HTP using unmanned aerial systems (UAS), or ground-based sensors

145 is providing high density phenotypic data that can be incorporated into breeding programs to 
146 increase genetic gain (Haghighattalab et al. 2016; Crain et al. 2018; Wang et al. 2020). Using

147 precision phenotyping for disease scoring can improve the capacity for rapid and non-biased

148 evaluation of large field-scale numbers of entries (Poland and Nelson 2011). Taken together

149 improvements in genomics and phenomics have the potential to aid breeding progress for BYD

150 resistance.

152 In an effort to accelerate the development of resistant lines, we combined high throughput 153 genotyping and phenotyping to assess BYD severity in a large panel of elite wheat lines. We

154 evaluated the potential of HTP data to accurately assess BYD severity as well as identify genetic 155 regions associated with BYD resistance and inform whole genome prediction to identify resistant 156 lines.

\section{Materials and Methods}

\section{Plant Material}

161 A total of 381 different wheat genotypes were characterized for BYD resistance, including 30

162 wheat cultivars and 351 advanced breeding lines in field nurseries over five years (Table S1). In 163 each nursery, an unbalanced set of 52 - 107 wheat entries were evaluated including both

164 cultivars and breeding lines (Table 1). The BYD susceptible cultivar 'Art' and BYD resistant

165 cultivar 'Everest' were included in all the nurseries (seasons) as checks.

\section{Field Experiments}

168 Nurseries for BYD field-screening were conducted during five consecutive wheat seasons (2015 $169-2016$ to 2019 - 2020) (Table 1). Seasons 2015 - 16 and 2016 - 17 were conducted at Kansas

170 State University (KSU) Rocky Ford experimental station $\left(39^{\circ} 13^{\prime} 45.60^{\prime \prime} \mathrm{N}, 96^{\circ} 34^{\prime} 41.21^{\prime \prime} \mathrm{W}\right)$, 171 while the 2017 - 18, 2018 - 19, and 2019-20 nurseries were planted at KSU Ashland Bottoms 172 experimental station $\left(39^{\circ} 07^{\prime} 53.76^{\prime \prime} \mathrm{N}, 96^{\circ} 37^{\prime} 05.20^{\prime \prime} \mathrm{W}\right)$. The nurseries were established for 173 natural infections by planting about three weeks earlier than the normal planting window in mid174 September. The susceptible cultivar 'Art' was planted as a spreader plot in the borders and as a 175 control check plot also with the resistant cultivar 'Everest'. The experimental unit was $1.5 \mathrm{~m} \times$ $1762.4 \mathrm{~m}$ with a six-row plot on $20 \mathrm{~cm}$ row spacing. 
178 A split-plot field design with two or three replications was used where the main plot was

179 insecticide treatment, and the split plot was the wheat genotype. Three replications were used

180 for proof of concept during the first two seasons but then two replications were chosen as a

181 balance of space and number of entries for the following seasons. For the treated replications the

182 seed were treated at planting with Gaucho XT (combination of insecticide and fungicide) at a

183 rate of $0.22 \mathrm{ml} / 100 \mathrm{~g}$ of seed, followed with foliar insecticide applications starting from

184 approximately $2-3$ weeks after planting through heading. Depending on field conditions, spray

185 treatments were conducted every $14-21$ days if average air temperatures remained above $10^{\circ} \mathrm{C}$.

186 Foliar insecticides were applied to the treated replications in a spray volume of $280.5 \mathrm{~L} / \mathrm{ha}$ using

187 a Bowman MudMaster plot sprayer equipped with TeeJet Turbo TwinJet tips. Insecticide

188 applications consisted of a rotation of Warrior II, Lorsban, and Mustang Max at rates of

$1890.14 \mathrm{~L} / \mathrm{ha}, 1.17 \mathrm{~L} / \mathrm{ha}$, and $0.29 \mathrm{~L} / \mathrm{ha}$, respectively. For the control insecticide treatment (untreated),

190 the seed were treated with Raxil MD (fungicide) at a rate of $0.28 \mathrm{ml} / 100 \mathrm{~g}$ of seed, and no foliar

191 insecticide applications were applied. Foliar fungicide Nexicor was applied to the whole

192 experiment at a rate of $0.73 \mathrm{~L} / \mathrm{ha}$, at both planting and heading, to control all other diseases so the

193 main disease pressure was focused on BYD.

\section{Phenotypic Data}

196 Individual plots were assessed for i) BYD severity characterized as the typical visual symptoms

197 of yellowing or purpling on leaves using a $0-100 \%$ visual scale, determined directly after spike

198 emergence by recording the proportion of the plot exhibiting the symptoms (Table 1), ii) manual

199 plant height (PTHT $\mathrm{M}$, meters), and iii) grain yield (GY, tons/ha). Experimental plots were

200 harvested using a Kincaid 8XP plot combine (Kincaid Manufacturing., Haven, KS, USA). Grain

201 weight, grain moisture and test weight measurements for each plot was recorded using a Harvest

202 Master Classic GrainGage and Mirus harvest software (Juniper Systems, Logan, UT, USA).

203 Visual phenotypic assessment was recorded using the Field Book phenoapp (Rife and Poland

204 2014). 


\section{High-Throughput Phenotyping}

207 To compliment the manually recorded phenotypic data, we applied HTP using a ground-based

208 proximal sensing platform or an UAS (Table 2). Seasons 2015 - 16 and 2016 - 17 were

209 characterized by the ground platform as described in Barker et al. (2016) and Wang et al. (2018).

210 For the other three seasons, we used a quadcopter DJI Matrice 100 (DJI, Shenzhen, China)

211 carrying a MicaSense RedEdge-M multispectral camera (MicaSense Inc., United States). The

212 HTP data was collected on multiple dates throughout the growth cycle from stem elongation to

213 ripening (GS 30 - 90; Zadoks et al. 1974) (Table 2). Flight plans were created using CSIRO

214 mission planner application and missions were executed using the Litchi Mobile App (VC

215 Technology Ltd., UK, https://uavmissionplanner.netlify.app/) for DJI Matrice100. The aerial

216 image overlap rate between two geospatially adjacent images was set to $80 \%$ both sequentially

217 and laterally to ensure optimal orthomosaic photo stitching quality. All UAS flights were set at

$21820 \mathrm{~m}$ above ground level at $2 \mathrm{~m} / \mathrm{s}$ and conducted within two hours of solar noon. To improve the

219 geospatial accuracy of orthomosaic images, white square tiles with a dimension of $0.30 \mathrm{~m} \times$

$220 \quad 0.30 \mathrm{~m}$ were used as ground control points and uniformly distributed in the field experiment

221 before image acquisition and surveyed to cm-level resolution using the Emlid REACH RS+

222 Real-Time Kinematic Global Navigation Satellite System unit (Emlid Ltd., HongKong, China).

224 An automated image processing pipeline (Wang et al. 2020) was used to generate the

225 orthomosaics and extract plot-level plant height (PTHT $(\mathrm{m})$, Singh et al. 2019) and the

226 normalized difference vegetation index (NDVI) (Rouse et al. 1974), calculated as:

$228 \quad$ NDVI $=\frac{\text { NIR-Red }}{\text { NIR+Red }}$

[Eq. 1]

where NIR and Red are the near-infrared and red bands of the multispectral images and NDVI is

231 the output image. Both traits were selected based on potential BYD characterization where the

232 most typical BYD symptoms include chlorosis and stunting of the plants, thus, influencing

233 NDVI and PTHT. 


\section{Statistical Data Analyses}

236 First, the adjusted mean best linear unbiased estimator (BLUE) was calculated for each entry for

237 all the different traits for each season (Table S1), using the following model:

$y_{i j k l m}=\mu+G_{i}+T_{j}+G T_{i j}+R_{k(j)}+B_{l(k j)}+C_{m(k j)}+e_{i j k l m}$

where $y_{i j k l m}$ is the phenotype for the trait of interest, $\mu$ is the overall mean, $G_{i}$ is the fixed effect

242 of the $i^{\text {th }}$ entry (genotype), $T_{j}$ is the fixed effect of the $j^{\text {th }}$ insecticide treatment, $G T_{i j}$ is the fixed

243 effect of the interaction between the $i^{\text {th }}$ entry and the $j^{\text {th }}$ insecticide treatment (genotype by

244 treatment effect), $R_{k(j)}$ is the random effect of the $k^{\text {th }}$ replication nested within the $j^{t h}$

245 insecticide treatment and distributed as iid $R_{k(j)} \sim N\left(0, \sigma_{R}^{2}\right), B_{l(k j)}$ is the random effect of the

$246 l^{\text {th }}$ row nested within the $k^{\text {th }}$ replication and $j^{\text {th }}$ treatment distributed as iid $B_{l(k j)} \sim N\left(0, \sigma_{B}^{2}\right)$,

$247 C_{m(k j)}$ is the random effect of the $m^{t h}$ column nested within the $k^{\text {th }}$ replication and $j^{t h}$ treatment

248 and assumed distributed as iid $C_{m(k j)} \sim N\left(0, \sigma_{C}^{2}\right)$, and $e_{i j k l m}$ is the residual for the $i j k l m^{t h}$ plot

249 and distributed as iid $e_{i j k l m} \sim N\left(0, \sigma_{e}^{2}\right)$. The 'Ime4' R package (Bates et al. 2014) was used for

250 fitting the models.

251

252 The BLUEs were used to inspect trait distributions and to calculate Pearson correlations between

253 all traits. In addition, BLUE values were used to calculate the reduction in GY for each entry as

254 the difference of GY between the untreated and insecticide treated main plots. This variable

255 reflects the level of BYD resistance of each entry, and it was used to perform GWAS and GS

256 analyses.

258 For NDVI and PTHT $_{\mathrm{D}}$, the plot-level observed values extracted for the different phenotypic dates 259 were fitted to a logistic non-linear regression model (Fox and Weisberg 2011) as, 
263 where is $y$ the phenotype for the trait of interest at the time-point $x$ measured as days after

264 January $1, \theta_{1}$ is the maximum value (upper asymptote) represented by the final PTHT or

265 maximum achieved NDVI, $\theta_{2}$ is the inflection point that represents the greatest rate of change in

266 the growth curve, either senescence for NDVI or height of growth, $\theta_{3}$ is the lag phase or onset of

267 senescence or growth rate from time $x$ where $\mathrm{x}$ is the calendar day of the year since January 1 ,

268 and $\varepsilon$ is the residual error (Figure S1). The "nlme" R package was used for model fitting

269 (Pinheiro et al. 2015). The model parameters obtained for each trait $\left(\theta_{1 N D V I}, \theta_{2 N D V I}, \theta_{3 N D V I}\right.$,

$270 \theta_{1 P T H T_{D}}, \theta_{2 P T H T_{D}}$, and $\left.\theta_{3 P T H T_{D}}\right)$ were used in addition to the other phenotypic traits to calculate

271 BLUEs, distributions, correlations, and BLUPs.

272

273 Secondly, we used a mixed linear model to calculate the best linear unbiased predictors (BLUPs)

274 for each entry in each nursery (season) (Table S1), using the same model as described in

275 equation 2 but defining $G_{i}, T_{j}$, and $G T_{i j}$ as random effects. BLUPs were used because of the

276 unbalanced nature of the data (not all lines were evaluated in all the seasons). The BLUPs

277 calculated for each season were then combined for GWAS and GS. Furthermore, we calculated

278 broad-sense heritability on a line-mean basis by splitting the data based on whole plot treatment

279 for insecticide treatments as:

$281 \quad H^{2}=\frac{\sigma_{G}^{2}}{\sigma_{G}^{2}+\frac{\sigma_{e}^{2}}{r}}$

[Eq. 4]

282

283 where $\sigma_{G}^{2}$ is the genotypic variance, $\sigma_{e}^{2}$ is the residual error variance, and $r$ is the number of

284 replications.

\section{Genotypic Data}

287 A total of 346 wheat entries were genotyped using genotyping-by-sequencing (GBS) (Poland et 288 al. 2012) and sequenced on an Illumina Hi Seq2000. Single nucleotide polymorphisms (SNPs)

289 were called using Tassel GBSv2 pipeline (Glaubitz et al. 2014) and anchored to the Chinese

290 Spring genome assembly v1.0 (Appels et al. 2018). SNP markers with minor allele frequency <

2910.01 , missing data $>85 \%$, or heterozygosity $>15 \%$ were removed from the analysis. After

292 filtering, we retained 29,480 SNPs markers that were used to investigate the population structure 
293 through principal component analysis (PCA), genome-wide association analysis (GWAS), and

294 GS. In addition, GBS data was used to run a bioinformatics pipeline to predict the presence or

295 absence of the translocated segment on chromomere 7DL carrying the $B d v 2$ gene for each entry

296 (Table S1). The prediction was done based on a modified alien predict pipeline (Gao et al.

297 2021). Briefly, alien or wheat specific tags were counted in the 7DL region and tabulated using

298 a training set of cultivars or lines that are known to be $B d v 2$ positive and negative. A simple

299 classification was done based on alien to wheat tag counts ratios.

301 Genome-Wide Association Analysis

302 The GWAS analysis was performed with a mixed linear model implemented in the 'GAPIT' R

303 package (Lipka et al. 2012) that includes principal components to account for population

304 structure as fixed effects and the individuals to explains familial relatedness as random effects,

$306 y=X \beta+Z u_{i}+e$

where $y$ is the vector of phenotypic BLUPs, $X$ and $Z$ are the incidence matrix of $\beta$ and $u_{i}$, respectively, with $u_{i}$ assumed $\sim \mathrm{N}\left(0,2 K_{i} \sigma_{i}^{2}\right)$ where $K$ is the individual kinship matrix, and $e$ is

311 the unknown residual variance. The false discovery rate correction with an experimental

312 significance level value of 0.01 was used to assess marker-trait associations. Manhattan plots

313 were generated with 'CMplot' package in R software (Yin 2020). PCA using GBS-SNPs was

314 performed in R language. Eigenvalues and eigenvectors were computed with 'e' function using

315 'A.mat' function and the 'mean' imputation method of 'rrBLUP' package (Endelman, 2011). To

316 declare a quantitative trait locus (QTL) we considered only the regions having several SNP

317 markers in linkage disequilibrium, clearly showing a peak. We did not consider regions with a

318 single SNP above the significant threshold as a QTL.

320 Genomic Selection

321 Using data from the five seasons, GS models using the genomic best linear unbiased predictor

322 (G-BLUP) were developed to assess predictive ability. A five-fold cross-validation method was

323 used to assess model accuracy where the data set was split into five sets based on season, with 
324 four seasons forming the training set and the fifth season serving as prediction set. This process

325 was repeated until all seasons were predicted. Along with predicting all other seasons from each season, a model was evaluated with a leave-two-out cross-validation strategy. This strategy was

327 used to get a better mix of years with and without disease incidence, where the training

328 population consisted of three seasons, and the remaining two seasons were predicted from the

329 combined training population. The GS model was fitted with the training population using

330 'rrBLUP' kin.blup function (Endelman 2011), the GS model equation was,

$332 y=W g+\varepsilon$

where $y$ is a vector of phenotypic BLUPs, $W$ is the design matrix of $g, g$ is the vector of genotypic values $\sim \mathrm{N}\left(0, K \sigma_{g}^{2}\right)$ and $\varepsilon$ is the vector of residual errors (Endelman 2011).

336 Predictive ability was assessed using Pearson's correlation $(r)$ between the predicted value (G-

337 BLUP) and the BLUP for the respective phenotype. In addition, for both GS strategies we also

338 tested the effect of adding the genotype of the $B d v 2$ loci as a fixed effect cofactor, using the

339 model,

$y=\mu+\boldsymbol{X} \beta+\boldsymbol{W g}+\varepsilon$

[Eq. 7]

343 which combines parameters described in equation 6 and $X$ is the matrix $(n \times 1)$ of individual

344 observation for presence or absence of $B d v 2$ and $\beta$ is the fixed effect for the $B d v 2$ measurements.

\section{Results}

\section{Phenotypic Data}

349 We analyzed five years of BYD field-screening nurseries (seasons 2015-16 to 2019-20)

350 characterizing a total of 381 wheat lines. The disease pressure and the expression of BYD

351 associated symptoms varied each season, however, we were able to observe a significant effect

352 of the insecticide treatment in all seasons (Figure 1). Across all seasons, BYD symptoms were

353 lower on the insecticide treated plots and both PTHT $_{M}$ and GY increased compared to the non-

354 treated control. Season 2016-17 had the most conducive conditions for BYD screening, resulting 
in high average severity and a larger difference between mean values for the treated vs untreated plots for all the collected traits (Figure 1). There was general consistency in order across all seasons with the susceptible check 'Art' ranked among the highest in BYD severity (Figure S2).

Phenotypic correlations between the traits showed a negative correlation between BYD and GY for all the seasons and a negative or no correlation between BYD and PTHTM (Figure S3). The same correlation trends were observed under insecticide treated and untreated plots. Broad-sense heritability was moderate to high for all the traits, ranging between 0.21 and 0.79 for the insecticide treated plots and between 0.41 and 0.84 for the untreated plots. Across all traits, the untreated insecticide replications showed higher $H^{2}$ values, with season 2016 - 17 showing the highest values (Figure 2).

For the HTP data collected (Table 2), we obtained three different parameters $\left(\theta_{1}, \theta_{2}\right.$, and $\left.\theta_{3}\right)$ for both $\mathrm{PTHT}_{\mathrm{D}}$ and NDVI after fitting a logistic regression model using the data collected during the experiments (2015-16 season data was not included due to lack of data quality) (Figure S1). Correlations between these parameters and the phenotypic traits collected manually were different for all the traits (Figure S3). For the insecticide untreated plots, BYD resulted in a negative correlation with $\theta_{2 N D V I}$ and a positive correlation with $\theta_{3 N D V I}$, in most of the field seasons. We did not find a clear correlation pattern between BYD and $P T H T_{D}$. For PTHTM we detected a positive correlation with $\theta_{1 P T H T_{D}}$ across all seasons, and for GY we observed a positive correlation with $\theta_{1 N D V I}$ and $\theta_{2 N D V I}$, and a negative correlation with $\theta_{3 N D V I}$ (Figure S3).

\section{Prediction of $B d v 2$ Resistance Gene}

We used GBS data to genotype the $B d v 2$ resistance gene located on a translocation segment from intermediate wheatgrass on chromosome 7DL of bread wheat. In total, 33 of the 346 wheat lines carried the Th. intermedium chromosomal translocation with $B d v 2$ (Table S1). Interestingly, 28 of these $B d v 2$ lines belonged to the same breeding cycle, entering the advanced yield nursery

382 stage of the KSU breeding program in the 2017 - 18 season. Furthermore, only 7 pedigrees are 383 represented within the $28 B d v 2$ entries, meaning that these lines are highly related. The 384 remaining $5 B d v 2$ lines were distributed in 2015-16 (n=3), 2018-19 (n=1), and $2019-20$ $385(\mathrm{n}=1)$, and none of the lines from the season $2016-17$ had the presence of $B d v 2$ (Table S1). 


\section{Population Structure}

388 We studied the population structure of 346 wheat lines using 29,480 GBS-derived SNP markers.

389 The PCA did not reveal a strong pattern of population structure (Figure 3). Moreover, the

390 variation explained by the first two principal components (4 and 3\%, respectively) also supports

391 the hypothesis of minimal population structure within a single breeding program. We observed

392 that most of the wheat cultivars released by KSU breeding program were located outside the

393 cluster grouping all the breeding lines (Figure 3A). Lines with the presence of $B d v 2$ clustered

394 together (Figure 3B), likely due to a related pedigree to the original source, and we did not

395 identify any evident pattern for BYD severity associated with the population structure (Figure

396 3C).

398 Genome-Wide Association Analysis

399 To investigate the genetic architecture of BYD we performed GWAS analyses for all collected 400 traits using the BLUP values for 346 lines and 29,480 SNP markers. The first two principal 401 components from PCA and the kinship matrix were included in the mixed model to account for 402 population structure and genetic relatedness. We found significant marker-trait associations for 403 BYD severity on chromosomes 5AS, 7AL, and 7DL (Figure 4A). The highest peak was 404 observed on the proximal end of chromosome 7DL, located at $571 \mathrm{Mbp}-637 \mathrm{Mbp}$. To test the 405 hypothesis that this association was explained by the resistance gene $B d v 2$ (located on 406 chromosome 7DL), we investigated the haplotypes defined by the 16 SNP markers associated 407 with BYD severity and were able to identify two haplotypes that exactly matched the presence or 408 absence of $B d v 2$ (Fig 4A). This same region was mapped using BYD severity and the presence 409 or absence of $B d v 2$ as a fixed covariate (Figure 4B). This analysis (Figure 4B) also detected a 410 peak on chromosome 7AL. Lastly, we explored the effect of $B d v 2$ on both BYD BLUEs and 411 BLUPs, and we observed that the presence of $B d v 2$ had a positive effect in reducing the disease 412 severity by approximantly $10 \%$ (Figure 5A). The significant peak on chromosome 5AS, located 413 at $46 \mathrm{Mbp}$ - $103 \mathrm{Mbp}$, was explained by 10 SNP markers, comprising two main haplotypes, one 414 of them associated with reduced BYD severity (Fig 5B). When we combined the different 5AS 415 haplotypes with $B d v 2$, we observed that the presence of $B d v 2$ had a positive effect, reducing the 416 levels of BYD when combined with both 5AS haplotypes (Figure 5C), and suggesting an 
417 additive effect. Compared to the associations found for $B d v 2$ (Fig 4B), we did not find any

418 strong evidence of marker trait associations for the other evaluated traits (Figure S4).

\section{Genomic Selection}

421 To evaluate the potential of GS to predict BYD disease severity, we fit several GS models to the 422 phenotypic BLUPs of BYD, $\mathrm{PTH}_{\mathrm{M}}$, and reduction in GY. Across all traits, to determine

423 predictive ability we used a five-fold cross validation where prediction ability ranged from -0.08-

424 0.26. There was relatively good predictive ability for BYD severity ranging between $0.06-$

425 0.26, in comparison with PTHT $_{M}$ and reduction in GY resulting in a lower range from $0.02-017$

426 and $-0.08-0.2$, respectively (Figure 6). Evaluating the conformation of the training population,

427 we observed that when including 2016-17 season, prediction abilities were the highest for BYD

428 but the lowest for the other two traits, implying that season 2016 - 17 was either a good season

429 to train the prediction models or a difficult season to predict based on available data.

431 To further investigate the power of GS, we developed models using a leave-two-out strategy,

432 where two seasons were excluded from the training population and used as the testing

433 population. We fitted GS models for all possible two-season combinations. This strategy

434 resulted in slightly smaller training populations which decreased overall predictive ability

435 (Figure 6). This result was evident for BYD predictions were excluding two seasons had a larger

436 negative impact.

438 Lastly, we evaluated the effect of adding information about the genotype of the $B d v 2$ resistance 439 gene as a phenotypic fixed covariate into the GS models. There were differences in the effect of $440 B d v 2$ on the predictive ability across BYD severity, $\mathrm{PTHT}_{\mathrm{M}}$, and GY, showing a large effect for 441 predicting BYD but almost no effect for PTHT $_{M}$ and reduction in GY (Figure 6). The improved 442 predictive ability for BYD was clearly reflected with the decrease of prediction ability obtained 443 when season 2017 - 18 was excluded from the training population since most of the lines with 444 the presence of $B d v 2$ were evaluated in that season. 


\section{Discussion}

\section{Phenotypic Data}

449 The success of breeding for BYD resistance is highly impacted by the ability to precisely

450 characterize breeding material and disease symptoms. Even though BYD is spread worldwide,

451 its incidence in a given year depends on several factors such as aphid pressure, planting date, and

452 environmental conditions (e.g., temperature, rainfall, frost, etc.). In this study, we evaluated

453 winter wheat advanced breeding lines during five seasons implementing a rigorous field-testing

454 approach, that ultimately enabled us to consistently have plots contrasting with BYD infection

455 and uninfected or low incident plots. Moreover, by using large yield-size plots we were able to

456 calculate the reduction in GY and use this parameter as an estimate of field resistance.

The expression of BYD symptoms, however, was highly inconsistent during the different seasons. Seasons 2015-16 and 2016-17 showed the best expression of the disease symptoms, supported by the wide range of BYD severity between treated and untreated replications (Figure 1). Interestingly, both these seasons were conducted in the same experimental field (Table 1),

462 suggesting that this location could favor the expression of BYD. Moreover, weather conditions 463 were variable for all the seasons, suggesting that these had a huge impact on the disease

464 occurrence. While temperature records were similar for all the seasons, precipitation records did 465 show some differences. Season 2017 - 18 was dryer than normal, with $34 \%$ less precipitation 466 than the 30 years historical average $(1981-2010)$. On the other hand, season 2018-19 was

467 wetter than normal, with 58\% more precipitation than the 30 years historical average (Table S2).

\section{High-Throughput Phenotyping}

470 Evaluating BYD resistance using visual phenotypic selection can be challenging due to the 471 complex nature of the disease and rater variability (Poland and Nelson 2011). The use of HTP

472 with UAS is gaining popularity within breeding programs because it further improves selection 473 based on classical phenotyping. Accurate phenotyping is crucial for understanding the genetic 474 basis of quantitative and complex traits like BYD. In this study, we used HTP to complement 475 the visual BYD scoring. This tool improved our capacity for rapid, non-destructive, and non476 biased evaluation of large field-scale numbers of entries for BYD resistance. We were able to 
477 determine strong correlation patterns between visual BYD severity and HTP derived parameters

478 (Figure S3). However, none of the traits collected with UAS had a common genetic base with

479 BYD severity (Figure 4 and Figure S4). Disease scoring using HTP is scaling fast among

480 breeding programs; however, how to effectively use this data remains challenging. Some studies

481 have shown that data collected with sensor-based tools can be substituted to improve classical

482 disease visual evaluation (Sankaran et al. 2010; Kumar et al. 2016; Zheng et al. 2018); however,

483 to the best of our knowledge this study is the first attempt to characterize BYD in wheat using

484 HTP.

Genome-Wide Association Analysis

487 Using GWAS we detected QTLs on chromosomes 5AS, 7AL, and 7DL for BYD severity BLUPs

488 values. Using GBS tags that mapped to known alien fragments, we confirmed $B d v 2$ resistance 489 gene was located at 7DL, and confirmed that the 7DL QTL was explained by the presence of the

$490 B d v 2$ resistance gene. Even though only 33 wheat lines were positive for the presence of $B d v 2$,

491 we still had enough power to detect its effect, suggesting that $B d v 2$ has a strong effect on BYD

492 under Kansas field conditions (Figure 5). The associations on chromosome 7AL, observed for

493 both BYD severity and $B d v 2$, suggest that the SNP markers on the 7AL peak may be miss-

494 anchored markers that should have mapped to 7DL. The relatively high heritability values

495 obtained for the untreated replications (Figure 2) allowed us to detect a minor QTL on 5AS.

496 Marza et al. (2005) reported a QTL at 38cM on the short arm of chromosome 5A associated with

497 yellowing symptoms caused by BYD, and it is possible that this is the same region yet more data

498 is needed to confirm if these QTLs are the same. The only other study reporting GWAS for BYD

499 in wheat was able to identify several markers associated with BYD resistance on chromosomes

$5002 \mathrm{~A}, 2 \mathrm{~B}, 6 \mathrm{~A}$, and 7A (Choudhury et al. 2019b). However, most of the association were explained

501 by individual SNP markers, and to date do not have any definitive biological link. GWAS

502 results for the other traits used in this study did not discover genomic regions associated with the

503 traits (Figure S4). Taken together, these results suggest that BYD resistance is not controlled by

504 any large effect loci that could easily be incorporated into the breeding program, thus GS could

505 be an efficient way to enhance BYD resistance. 


\section{Genomic Selection}

508 We evaluated several different GS models to identify the best approach for predicting BYD

509 (Figure 6). Overall, we observed some trends including i) incorporating years with consistent

510 BYD disease data in the training population increased the model predictive ability, ii) predicting

511 years with high disease pressure is difficult, iii) using major effect QTL, such as $B d v 2$, had

512 increased prediction performance, suggesting that it is responsible for much of the predictive

513 power. These results suggest that GS based on G-BLUP with $B d v 2$ as fixed effects would lead to

514 the greatest genetic gain for BYD breeding. Using selected major QTL as a fixed effect to

515 improve GS models was suggested in a simulation study (Bernardo 2014) and demonstrated with

516 empirical studies (Rutkoski et al. 2014). Nonetheless, using $B d v 2$ as a fixed effect in our GS

517 strategies did not consistently improve the predictive ability for $\mathrm{PTH}_{\mathrm{M}}$ or reduction in GY (Rice

518 and Lipka 2019). However, there was not a consistent distribution of $B d v 2$ allele across the

519 cohorts. BYD predictions were low compared to other disease (reviewed by Poland and

520 Rutkoski 2016). However, since this is the first report of GS for BYD resistance in wheat, we do

521 not have similar results to make better comparisons. BYD has traditionally been reported to

522 have low $H^{2}$ (Tola and Kronstad 1984; Choudhury et al., 2019b) and in this study, even with

523 well managemed plots that often had $H^{2}$ approaching 0.8 , we still had difficulty reproducing

524 these results year to year as evidence of the challenge of studying this pathosystem. Moreover,

525 the correlation between HTP parameters and BYD phenotypes was interesting, but not sufficient

526 to be useful in combination with GS in the germplasm tested.

\section{Conclusions}

529 We were able to show that $B d v 2$ has a major effect controlling BYD resistance in the KSU

530 breeding germplasm. Apart from the known $B d v 2$ and a potentially novel 5AS region, we did

531 not find evidence of other regions controlling BYD resistance supporting the hypothesis of

532 limited resistance available in the current wheat gene pool and the highly polygenic nature of the

533 trait. Moreover, our study was the first attempt to characterize and improve BYD field-

534 phenotyping using HTP and apply GS to predict the disease. HTP traits showed strong

535 correlation patterns with BYD severity, however, none of these parameters shared a common

536 genetic architecture with BYD severity. The GS predictive ability results that we found in this

537 study open the door for further improvement and testing GS implementation for breeding for 
BYD resistance. Continuing the improvement of BYD characterization and the search of new sources of resistance using species related to wheat, will be crucial to broadening the resistant genes available to introgress into wheat germplasm.

\section{Data Availability Statement}

544 Supplemental material, including raw and analyzed phenotypic data, genotypic data,

545 supplementary tables and figures, and basic plot scripts are available at Dyrad

546 doi:10.5061/dryad.ncjsxkswd (temporary link: https://datadryad.org/stash/share/xkKdr62QYB-

547 YA93mkzq18 4yFUgwdnvv0uZUyuEHpAI) and GitHub

548 https://github.com/umngao/wsm1_bdv2

\section{Supplementary data description}

550 Table S1 - List of wheat entries phenotypically evaluated in the study. The table includes the

551 type of entry (cultivar or breeding line), the season that the entry was evaluated, the result for the

552 prediction of the presence/absence of the segment carrying the resistance gene $B d v 2$, and the best

553 linear unbiased predictors (BLUPs) for all the phenotypic traits collected.

554 Table S2 - Precipitation (inches) during the five field seasons in Riley County, KS, where

555 Rocky Ford and Ashland Bottoms experimental units are located. Normal temperature is defined

556 as a 30-year average from 1981 - 2010. Data was obtained from Kansas State University

557 (http://climate.k-state.edu/precip/county/)

558 Figure S1 - Growth trajectories and adjustment of the non-linear regression model of wheat

559 lines for A-B) normalized difference vegetation index (NDVI) and C-D) digital plant height

560 (meters). The data used correspond to season 2016-17 phenotypic data. Calendar days is the

561 number of days starting at January 1, 2017.

562 Figure S2 - Boxplots showing the phenotypic response of the wheat checks 'Art' (susceptible)

563 and 'Everest' (tolerant) for A) barley yellow dwarf (BYD) disease severity (\%), B) manual plant

564 height ( $\left.\mathrm{PTHT}_{\mathrm{M}}\right)(\mathrm{m})$ and $\left.\mathrm{C}\right)$ grain yield (GY) (tons/ha). Adjusted phenotypic values are shown

565 for both insecticide treatment replications (treated and untreated).

566 Figure S3 - Scatterplots showing distribution and Pearson's correlation values for the

567 phenotypic traits studied during all the field seasons under two insecticide treatments (treated 
568 and untreated). A-B) season 2016 - 17, C-D) season 2017 - 18, E-F) season 2018 - 19, and G-H)

569 season $2019-20$.

570 Figure S4 - Manhattan plots showing genome-wide association analysis (GWAS) results for the

571 phenotypic traits collected during the study.

572

\section{Acknowledgements}

574 This material is based upon work supported by Kansas Wheat Commission Award No: B65336

575 "Integrative and Innovative Approaches to Diminish Barley Yellow Dwarf Epidemics Kansas

576 Wheat". PS was supported through a U.S. Fulbright-ANII Uruguay Scholarship. Any opinions,

577 findings, and conclusions or recommendations expressed in this material are those of the

578 author(s) and do not necessarily reflect the views of industry partners. 


\section{Literature Cited}

Appels, R., K. Eversole, C. Feuillet, B. Keller, J, Rogers, et al., 2018 Shifting the limits in wheat research and breeding using a fully annotated reference genome. Science, 361(6403) http://dx.doi. org/10.1126/ science.aar7191

Aradottir, G. I., and L. Crespo-Herrera, 2021 Host plant resistance in wheat to barley yellow dwarf viruses and their aphid vectors: a review. Current Opinion in Insect Science, 2021, 45:59-68 https://doi.org/10.1016/j.cois.2021.01.002

Ayala-Navarrete, L., and P. Larkin, 2011 Wheat virus diseases: breeding for resistance and tolerance. World wheat book: a history of wheat breeding, Lavoisier, Paris, 2, 1073-107.

Ayala, L., M. Henry, M. Van Ginkel, R. Singh, B. Keller, et al., 2002 Identification of QTLs for BYDV tolerance in bread wheat. Euphytica, 128(2), 249-259 https://doi.org/10.1023/A:1020883414410

Ayala, L., M. Van Ginkel, M. Khairallah, B. Keller, and M. Henry, 2001 Expression of Thinopyrum intermedium-derived Barley yellow dwarf virus resistance in elite bread wheat backgrounds. Phytopathology, 91(1), 55-62 https://doi.org/10.1094/PHYTO.2001.91.1.55

Banks, P. M., J. L. Davidson, H. Bariana, and P. J. Larkin, 1995 Effects of barley yellow dwarf virus on the yield of winter wheat. Australian Journal of Agricultural Research, 46(5), 935-946

Barker III, J., N. Zhang, J. Sharon, R. Steeves, X. Wang, et al., 2016 Development of a fieldbased high-throughput mobile phenotyping platform. Computers and Electronics in Agriculture, 122, 74-85 https://doi.org/10.1016/j.compag.2016.01.017

Bates, D., M. Mächler, B. Bolker, and S. Walker, 2014 Fitting linear mixed-effects models using lme4. arXiv preprint arXiv: 1406.5823

Bernardo, R., 2014 Genome-wide selection when major genes are known. Crop Science, 54(1), 68-75 https://doi.org/10.2135/cropsci2013.05.0315

Bockus, W. W., E. D. De Wolf, and T. Todd, 2016 Management strategies for barley yellow dwarf on winter wheat in Kansas. Plant Health Progress, 17(2), 122-127 https://doi.org/10.1094/PHP-RS-15-0050 
Brettell, R. I. S., P. M. Banks, Y. Cauderon, X. Chen, z. Cheng, et al., 1988 A single wheatgrass chromosome reduces the concentration of barley yellow dwarf virus in wheat. Annals of Applied Biology, 113(3), 599-603 https://doi.org/10.1111/j.1744-7348.1988.tb03337.x

Choudhury, S., H. Hu, Y. Fan, P. Larkin, M. Hayden, et al., 2019a Identification of new QTL contributing to barley yellow dwarf virus-PAV (BYDV-PAV) resistance in wheat. Plant Disease, 103(11), 2798-2803 https://doi.org/10.1094/PDIS-02-19-0271-RE Barley yellow dwarf virus infection affects physiology, morphology, grain yield and flour pasting properties of wheat. Crop and Pasture Science, 70(1), 16-25 https://doi.org/10.1071/CP1836

Comeau, A., and S. Haber, 2002 Breeding for BYDV tolerance in wheat as a basis for a multiple stress tolerance strategy. Barley Yellow Dwarf Disease: Recent Advances and Future Strategies, 82

D’arcy, C. J., 1995 Symptomatology and host range of barley yellow dwarf. Barley yellow dwarf, 40, 9-28 Package rrBLUP. The Plant Genome, 4(3), 250-255. https://doi.org/10.3835/plantgenome2011.08.0024 
Foresman, B. J., R. E. Oliver, E. W. Jackson, S. Chao, M. P. Arruda, et al., 2016 Genome-wide association mapping of barley yellow dwarf virus tolerance in spring oat (Avena sativa L.). PloS one, 11(5), e0155376 https://doi.org/10.1371/journal.pone.0155376

Fox, J., and S. Weisberg, 2011 Nonlinear regression and nonlinear least squares in R. In: J. Fox and S. Weisberg, An R companion to applied regression. 2nd ed. SAGE Publications, Los Angeles, CA

Gao, L., D. H. Koo, P. Juliana, T. Rife, D. Singh, et al., 2021 The Aegilops ventricosa 2Nv S segment in bread wheat: cytology, genomics, and breeding. Theoretical and Applied Genetics, 134(2), 529-542. https://doi.org/10.1007/s00122-020-03712-y

Gaunce, G. M., and W. W. Bockus, 2015 Estimating Yield Losses Due to Barley Yellow Dwarf on Winter Wheat in Kansas Using Disease Phenotypic Data. Plant Health Progress, 16(1), 1-6 https://doi.org/10.1094/php-rs-14-0039

Girvin, J., R. J. Whitworth, L. M. A. Rojas, and C. M. Smith, 2017 Resistance of select winter wheat (Triticum aestivum) cultivars to Rhopalosiphum padi (Hemiptera: Aphididae). Journal of Economic Entomology, 110(4), 1886-1889 https://doi.org/10.1093/jee/tox164

Glaubitz, J. C., T. M. Casstevens, F. Lu, J. Harriman, R. Elshire, et al., 2014 TASSEL-GBS: A High-Capacity Genotyping by Sequencing Analysis Pipeline. PLoS ONE, 9(2), e90346 https://doi.org/10.1371/journal.pone.0090346

Haghighattalab, A., L. G. Pérez, S. Mondal, D. Singh, D. Schinstock, et al., 2016 Application of unmanned aerial systems for high throughput phenotyping of large wheat breeding nurseries. Plant Methods, 12(1), 1-15 https://doi.org/10.1186/s13007-016-0134-6

Hollandbeck, G. F., E. DeWolf, and T. Todd, 2019 Kansas cooperative plant disease survey report. Preliminary 2019 Kansas wheat disease loss estimates. October 2, 2019 https://agriculture.ks.gov/divisionsprograms/plant-protect-weed-control/reports-andpublications

Jahier, J., F. Chain, D. Barloy, A. M. Tanguy, J. Lemoine J, et al., 2009 Effect of combining two genes for partial resistance to Barley yellow dwarf virus-PAV (BYDV-PAV) derived from Thinopyrum intermedium in wheat. Plant Pathol 2009, 58:807-814 https://doi.org/10.1111/j.1365-3059.2009.02084.x 
Jarošová, J., E. Beoni, and J. K. Kundu, 2016 Barley yellow dwarf virus resistance in cereals: Approaches, strategies, and prospects. Field Crops Research, 198, 200-214 https://doi.org/10.1016/j.fcr.2016.08.030

Jensen, S. G., and J. W. Van Sambeek, 1972 Differential Effects of Barley Yellow Dwarf Virus on the Physiology of Tissues of Hard Red Spring Wheat. Phytopathology, 62(2), 290 https://doi.org/10.1094/phyto-62-290

Kumar, S., M. S. Röder, R. P. Singh, S. Kumar, R. Chand, et al., 2016 Mapping of spot blotch

Larkin, P. J., P. M. Banks, E. S. Lagudah, R. Appels, C. Xiao, et al., 1995 Disomic Thinopyrum intermedium addition lines in wheat with barley yellow dwarf virus resistance and with rust resistances. Genome, 38(2), 385-394 https://doi.org/10.1139/g95-050

Lin, Z. S., Z. F. Cui, X. Y. Zeng, Y.Z. Ma, Z. Y. Zhang, et al., 2007 Analysis of wheatThinopyrum intermedium derivatives with BYDV-resistance: Analysis of wheatTh.intermedium derivatives. Euphytica, 158(1-2), 109-118 https://doi.org/10.1007/s10681-007-9435-1

Marza, F., G. H. Bai, B. F. Carver, and W. C. Zhou, 2005 Quantitative trait loci for yield and

Meuwissen, T. H., B. J. Hayes, and M. E. Goddard, 2001 Prediction of total genetic value using genome-wide dense marker maps. Genetics, 157(4), 1819-1829 https://doi.org/10.1093/genetics/157.4.1819

Miller, W. A., and L. Rasochová, 1997 Barley yellow dwarf viruses. Annual Review of Phytopathology, Vol. 35, pp. 167-190 https://doi.org/10.1146/annurev.phyto.35.1.167 diversity in wheat to enhance grain yield, climate resilience, disease and insect pest 
resistance and nutrition through conventional and modern breeding approaches. Frontiers in plant science, 7, 991 https://doi.org/10.3389/fpls.2016.00991

Perry, K. L., F. L. Kolb, B. Sammons, C. Lawson, G. Cisar, et al., 2000 Yield effects of Barley yellow dwarf virus in soft red winter wheat. Phytopathology, 90(9), 1043-1048 https://doi.org/10.1094/PHYTO.2000.90.9.1043

Peiris, K. H., R. L. Bowden, T. C. Todd, W. W. Bockus, M. A. Davis, et al., 2019 Effects of barley yellow dwarf disease on wheat grain quality traits. Cereal Chemistry, 96(4), 754764 https://doi.org/10.1002/cche.10177 Pinheiro, J., D. Bates, S. DebRoy, and D. Sarkar, 2015 R Core Team. 2015. nlme: linear and nonlinear mixed effects models. $\mathrm{R}$ package version 3.1-120. $\mathrm{R}$ package version, 3-1.

Poland, J., 2015 Breeding-assisted genomics. Current Opinion in Plant Biology, Vol. 24, pp. 119-124 https://doi.org/10.1016/j.pbi.2015.02.009

Poland, J. A., and R. J. Nelson, 2011 In the eye of the beholder: The effect of rater variability and different rating scales on QTL mapping. Phytopathology, 101(2), 290-298 https://doi.org/10.1094/PHYTO-03-10-0087

Poland, J. A., P. J. Brown, M. E. Sorrells, and J. L. Jannink, 2012 Development of high-density genetic maps for barley and wheat using a novel two-enzyme genotyping-by-sequencing approach. PloS one, 7(2), e32253 https://doi.org/10.1371/journal.pone.0032253

Poland, J., and J. Rutkoski, 2016 Advances and Challenges in Genomic Selection for Disease Resistance. Annual Review of Phytopathology, 54(1), 79-98 https://doi.org/10.1146/annurev-phyto-080615-100056

Qualset, C. O., J. C. Williams, M. A. Topcu, and H. E. Vogt, 1973 The barley yellow-dwarf virus in wheat: importance, sources of resistance, and heritability. In Proceedings, Fourth International Wheat Genetics Symposium, Columbia, Missouri (pp. 465-470)

Rice, B., and A. E. Lipka, 2019 Evaluation of RR-BLUP genomic selection models that 
Rife, T. W., and J. A. Poland, 2014 Field Book: An Open-Source Application for Field Data Collection on Android. Crop Science, 54(4), 1624-1627 https://doi.org/10.2135/cropsci2013.08.0579

Rouse, J. W., R. H. Haas, J. A. Schell, and D. W. Deering, 1974 Monitoring vegetation systems in the Great Plains with ERTS. NASA special publication, 351(1974), 309

Rutkoski, J. E., J. A. Poland, R. P. Singh, J. Huerta-Espino, S. Bhavani, et al., 2014 Genomic Selection for Quantitative Adult Plant Stem Rust Resistance in Wheat. The Plant Genome, 7(3) https://doi.org/10.3835/plantgenome2014.02.0006

Sankaran, S., A. Mishra, R. Ehsani, and C. Davis, 2010 A review of advanced techniques for detecting plant diseases. Computers and Electronics in Agriculture, 72(1), 1-13 https://doi.org/10.1016/j.compag.2010.02.007

Savary, S., L. Willocquet, S. J. Pethybridge, P. Esker, N. McRoberts, et al., 2019 The global

Shah, S. J. A., M. Bashir, and N. Manzoor, 2012 A review on barley yellow dwarf virus. In Crop

Production for Agricultural Improvement, Vol. 9789400741164, pp. 747-782 https://doi.org/10.1007/978-94-007-4116-4 29

Sharma, H., H. Ohm, L. Goulart, R. Lister, R. Appels, et al., 1995 Introgression and

Singh, R. P., P.A. Burnett, M. Albarran, and S. Rajaram, 1993 Bdv1: a gene for tolerance to barley yellow dwarf virus in bread wheats. Crop Science, 33(2), 231-234 https://doi.org/10.2135/cropsci1993.0011183X003300020002x

Singh, D., X. Wang, U. Kumar, L. Gao, M. Noor, et al., 2019 High-throughput phenotyping

Tola, J. E., and W. E. Kronstad, 1984The genetics of resistance to barley yellow dwarf virus in wheat. In Barley Yellow Dwarf Workshop, Mexico, DF (Mexico), 6-8 Dec 1983. 
Walls, J., E. Rajotte, and C. Rosa, 2019 The past, present, and future of barley yellow dwarf management. Agriculture (Switzerland), 9(1), 1-16 https://doi.org/10.3390/agriculture9010023

Wang, X., P. Silva, N. M. Bello, D. Singh, B. Evers, et al., 2020 Improved Accuracy of HighThroughput Phenotyping from Unmanned Aerial Systems by Extracting Traits Directly from Orthorectified Images. Frontiers in Plant Science, 11, 1616 https://doi.org/10.3389/fpls.2020.587093

Wang, X., D. Singh, S. Marla, G. Morris, and J. Poland, 2018 Field-based high-throughput phenotyping of plant height in sorghum using different sensing technologies. Plant Methods, 14(1), 53 https://doi.org/10.1186/s13007-018-0324-5

768 Zadoks, J. C., T. T. Chang, and C. F. Konzak, 1974 A decimal code for the growth stages of cereals. Weed research 14.6 (1974): 415-421

Yin, LiLin, 2020 CMplot: Circle Manhattan Plot. R package version 3.6.2 https://CRAN.Rproject.org/package $=\mathrm{CMplot}$

772 Yu, J., G. Pressoir, W. H. Briggs, I. V. Bi, M. Yamasaki, et al., 2006 A unified mixed-model method for association mapping that accounts for multiple levels of relatedness. Nature genetics, 38(2), 203-208 https://doi.org/10.1038/ng1702

Zhang, Z., Z. Lin, and Z. Xin, 2009 Research progress in BYDV resistance genes derived from

778 Zheng, Q., W. Huang, X. Cui, Y. Dong, Y. Shi, et al., 2018 Identification of Wheat Yellow Rust 779 Using Optimal Three-Band Spectral Indices in Different Growth Stages. Sensors, 19(1), $780 \quad 35$ https://doi.org/10.3390/s19010035 
Table 1 - Field experimental details for the five wheat nurseries

\begin{tabular}{|c|c|c|c|c|c|}
\hline Season & $2015-2016$ & $2016-2017$ & $2017-2018$ & $2018-2019$ & $2019-2020$ \\
\hline \multirow{2}{*}{ Location } & \multicolumn{2}{|c|}{ Rocky Ford farm } & \multicolumn{3}{|c|}{ Ashland Bottoms farm } \\
\hline & \multicolumn{2}{|c|}{$39^{\circ} 13^{\prime} 45.60^{\prime \prime} \mathrm{N}, 96^{\circ} 34^{\prime} 41.21^{\prime \prime} \mathrm{W}$} & \multicolumn{3}{|c|}{$39^{\circ} 07^{\prime} 53.76^{\prime \prime} \mathrm{N}, 96^{\circ} 37^{\prime} 05.20^{\prime \prime} \mathrm{W}$} \\
\hline Planting Date & Sep. 17,2015 & Sep. 12, 2016 & Sep. 19, 2017 & Sep. 17, 2018 & Sep. 17, 2019 \\
\hline Number of Entries & 68 & 52 & 81 & 81 & 107 \\
\hline Number of Plots & 504 & 360 & 400 & 392 & 684 \\
\hline Field Design & \multicolumn{5}{|c|}{ split-plot with insecticide treatment as major factor effect and wheat genotype as secondary factor } \\
\hline Replications & 3 & 3 & 2 & 2 & 2 \\
\hline Plot Size & \multicolumn{5}{|c|}{6 rows plots $-1.5 \mathrm{~m} \times 2.4 \mathrm{~m}$} \\
\hline BYD Evaluation & April 28, 2016 & May 12, 2017 & May 19, 2018 & May 13, 2019 & May 19,2020 \\
\hline Harvesting Date & June 20, 2016 & June 19, 2017 & June 23, 2018 & June 28, 2019 & June 25,2020 \\
\hline
\end{tabular}


Table 2 - Dates of high-throughput phenotypic data collection and details of image acquisition in the five wheat nurseries screened for BYD, Kansas, USA (2015-2020).

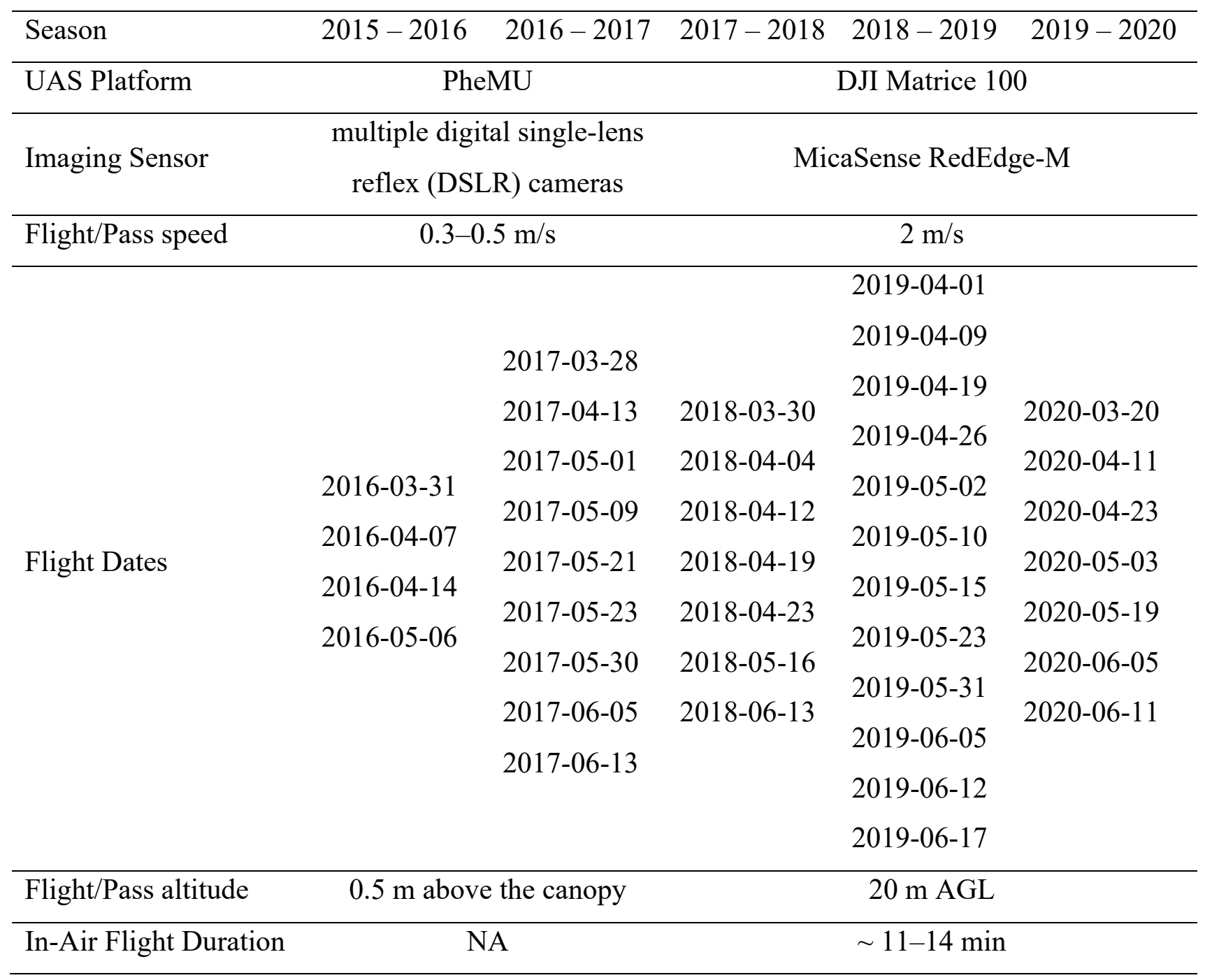



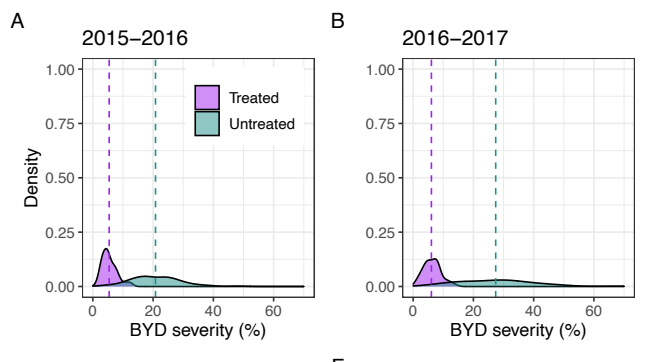

F

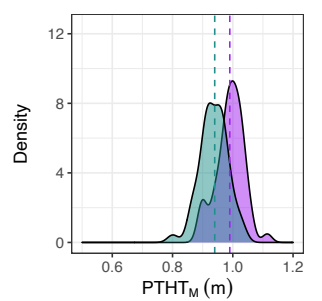

$\mathrm{K}$

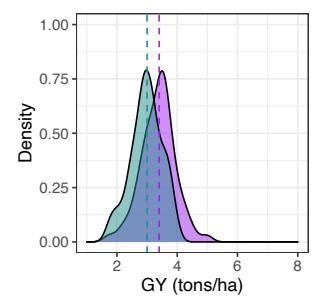

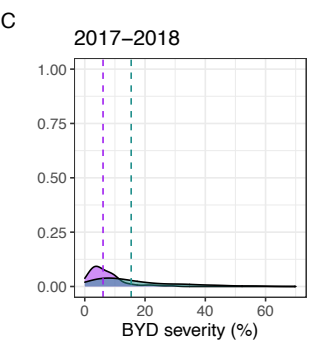

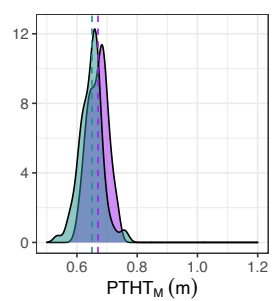

L
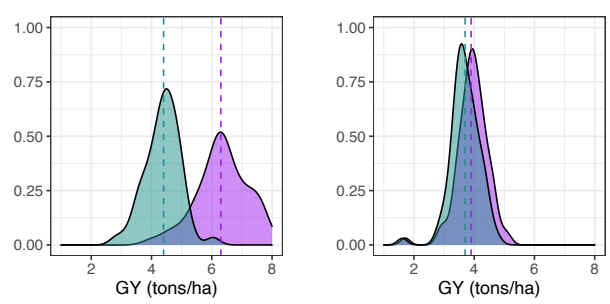

$\mathrm{H}$

M
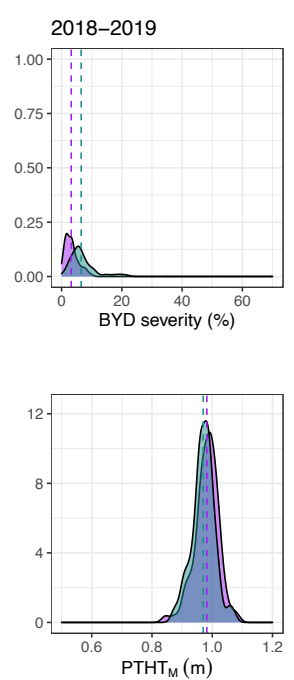

E

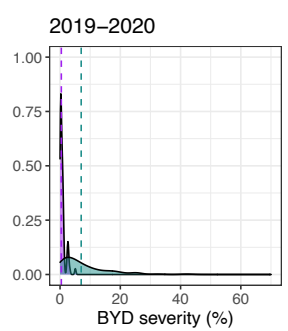

I

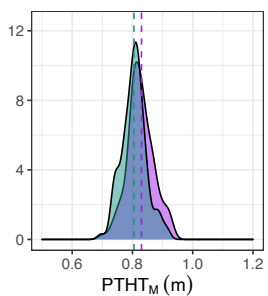

N
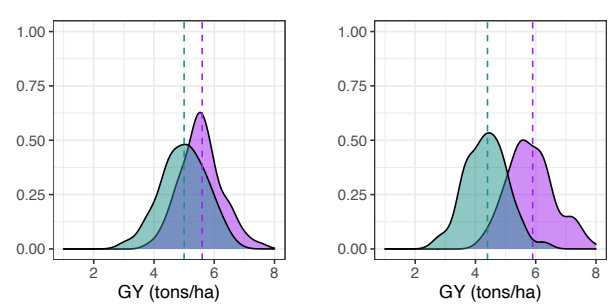

Figure 1 Adjusted phenotypic values for the traits collected manually for five different field seasons (2015-2016 to 2019-2020). A-E): barley yellow dwarf (BYD) severity (\%) characterized as the typical visual symptoms of yellowing/purpling on leaves using a $0-100 \%$ visual scale, FI) manual plant height/stunting $\left(\mathrm{PTHT}_{\mathrm{M}}\right)$ (meters), note that the trait was not recorded for the 2015 - 2016 season, and J-N) grain yield (GY) (tons/ha). Insecticide-treated and untreated replications are represented by purple and green, respectively. The dashed line represents the mean value for the trait in each treatment 


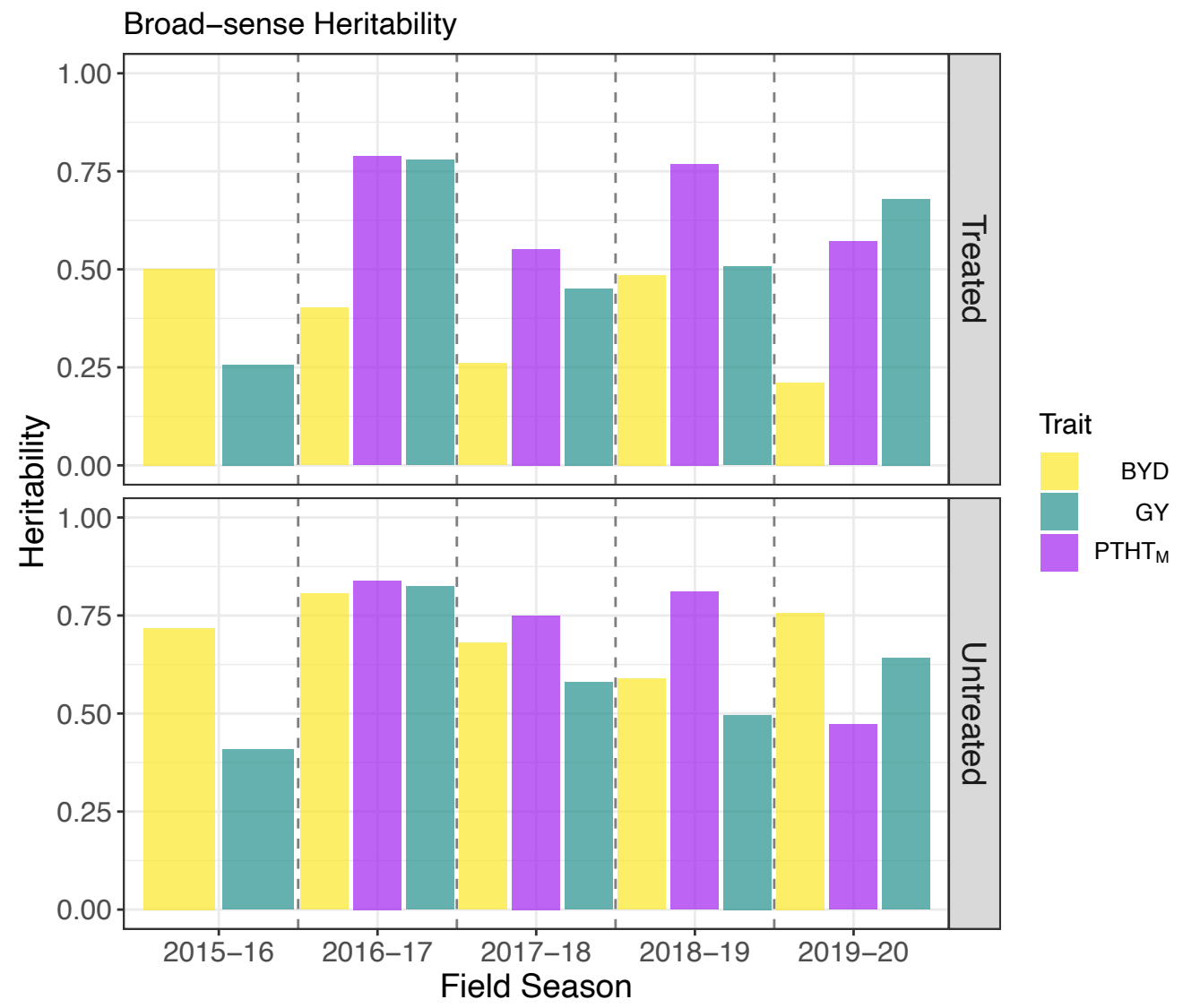

Figure 2 Broad-sense heritability of wheat phenotypic traits collected manually, including visual barley yellow dwarf (BYD) score, plant height (РTHTM) and grain yield (GY) during five different field seasons under two insecticide treatments. 
A

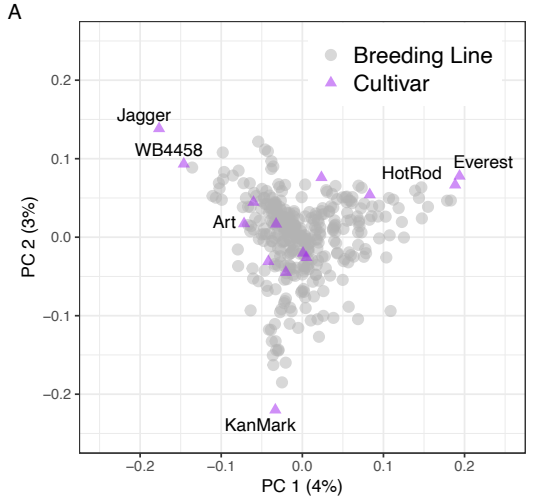

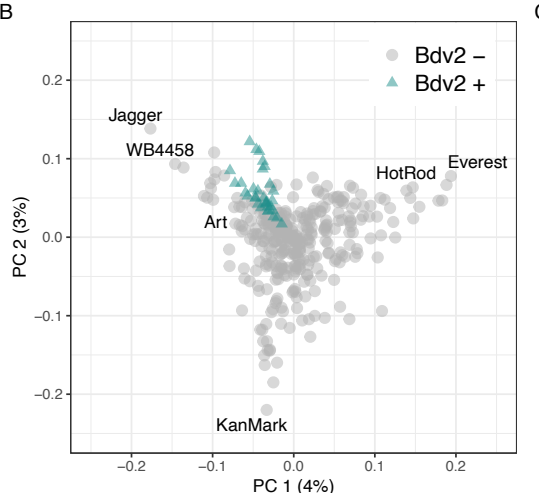

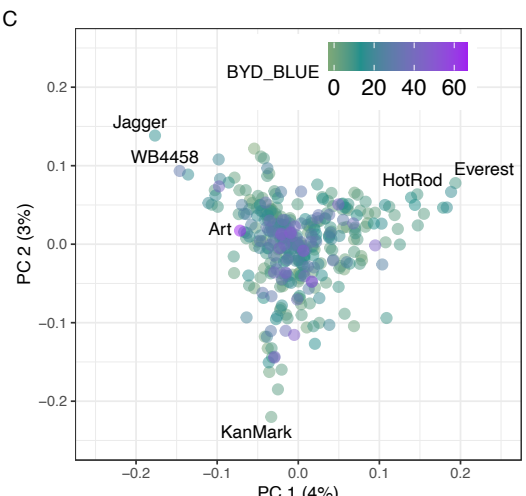

Figure 3 Scatterplot of the first two principal component axis, made from principal component analysis on the marker matrix, $n=357$ wheat lines, markers $=29,480$. Each data point represents an individual wheat line that is color-coded by A) breeding status, B) prediction of $B d v 2$ presence/absence, and C) adjusted mean for BYD severity (BYD BLUE) scored visually. Total variance explained by each principal component (PC) is listed on the axis. 

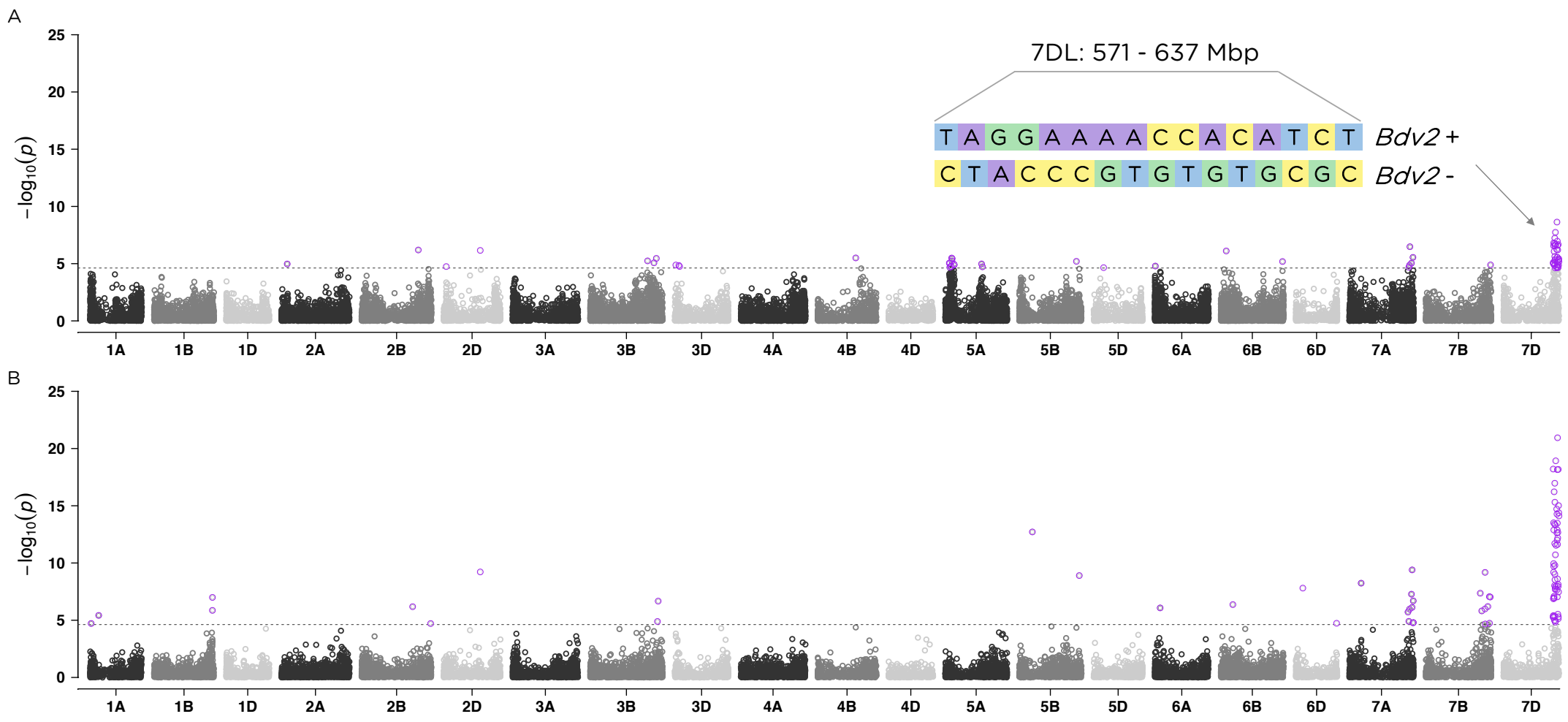

Figure 4 Manhattan plots showing the marker-trait associations using 346 wheat accessions and 29,480 SNP markers obtained with genotyping-by-sequencing (GBS) for A) BYD severity and B) presence/absence of $B d v 2$ resistance gene. The 21 labeled wheat chromosomes with physical positions are on the $\mathrm{x}$-axis and $\mathrm{y}$-axis is the $-\log 10$ of the $\mathrm{p}$-value for each SNP marker. Horizontal dashed lines represent the false discovery rate threshold at 0.01 level and data points highlighted in purple and above the threshold represent SNPs significantly associated with the trait. In panel a, the length of the region and the haplotypes defined by the significant SNP markers is displayed. 

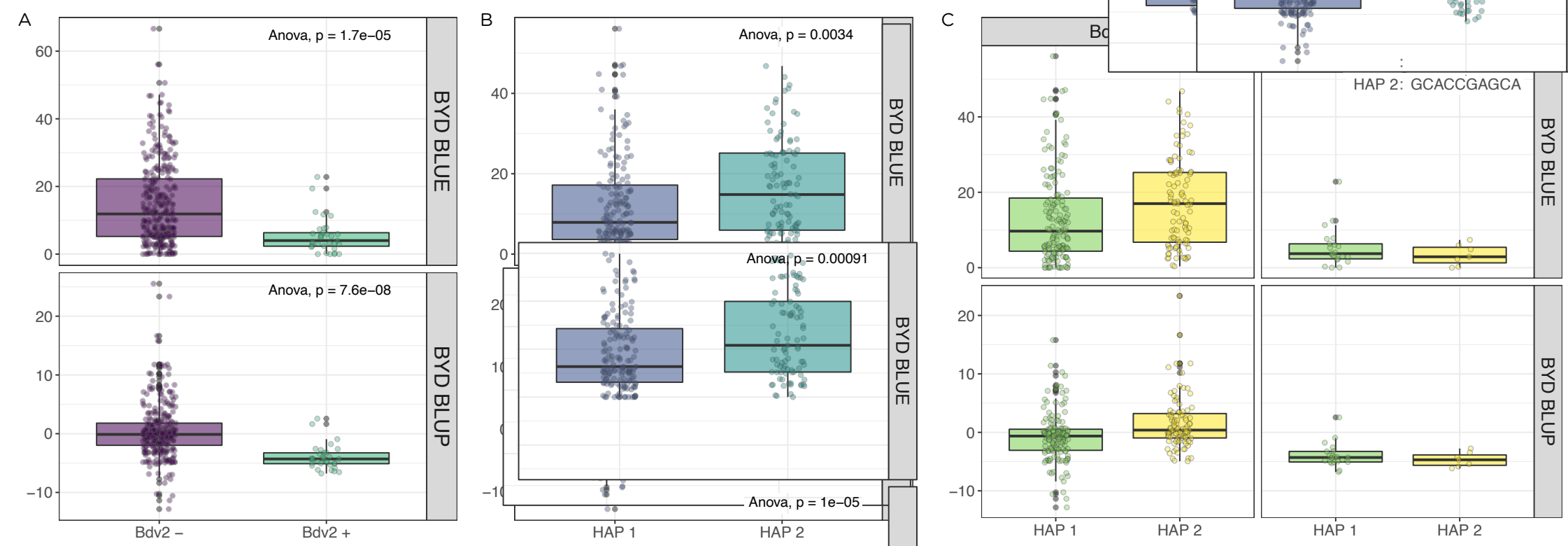

Figure 5 Measurement of barley yellow dwarf disease severity in wheat based on certain haplotype effects were panel A) represents the translocation segment carrying the resistance gene Bdv2, B) displays the two haplotypes for the significant region on chromosome 5AS, and $\mathrm{C}$ ) shows the combination of Bdv2 resistance gene and 5A haplotype. Boxplots showing the significant reduction of BYD disease severity by averaging the phenotypic best linear unbiased estimated (BLUE) or best linear unbiased predicted (BLUP) values for the lines. 


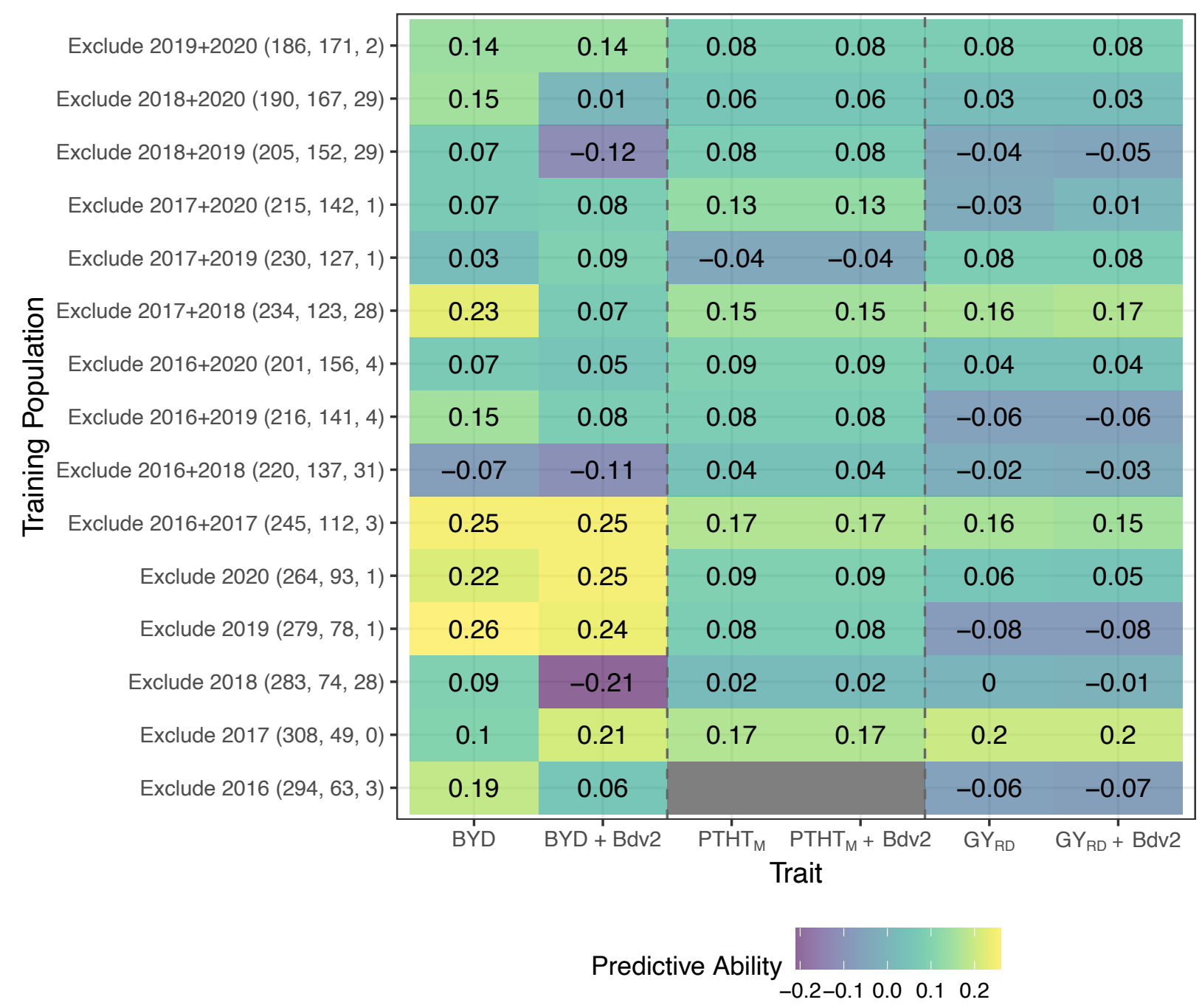

Figure 6 Genomic selection model predictive ability where each column represents one trait, and each row shows the conformation of the training population including size of training and testing population and number of lines with presence of $B d v 2$ resistance gene. The value in each cell represents the predictive ability which is the correlation between the GS predicted value (GBLUP) and the phenotypic best linear unbiased predictor (BLUP). 